\title{
Author's Foreword
}

In science as in other fields a progressive loss of individuality is taking its course. At the same time, historical perspectives fade. It is as if there were, in the forward press of research activity, no longer time for a backward look. Yet every man knows that the generation of today stands on the shoulders of great predecessors. Understanding of the work of these pioneers, however, becomes too easily assimilated into the anonymous bulk of the past. How their results developed step by step, how personal traits appear in their work, is scarcely asked.

This author has often felt the limitation of historical and human background to be a genuine deprivation. Hence, when a few years ago he was invited by the editor of the series "Grosse Naturforscher," Dr. Heinz Degen (Akademische Verlagsgesellschaft, Stuttgart), to write a biography of Theodor Boveri, the great cytologist of the turn of the last century, he set himself two tasks: to depict this rich personality and to present not only the scientific work itself, but, in so far as possible, the inner trend that the work followed.

This aim had a particular fascination since Boveri belonged to the classical period when cytology and genetics were becoming united into one field; the appeal was all the more powerful because Boveri was not only the discover of fundamental facts, but at the same time the creator of important general concepts that had a 
far reaching influence on the whole research field. On the other hand, one who has lived during the last decades has become aware of the rapidity with which research fields shift. In the course of a generation after Boveri's death, an extremely large number of new methods have been introduced, such as the refined biochemical techniques and electron microscopy. Last but not least, new organisms have been made available for research, such as the fruit fly Drosophila. All this was a challenge to place Boveri's work in perspective in the large historical frame.

The present author first met Boveri in Ig05 when, as a student, he came to Boveri's institute at Würzburg to work for the doctorate, and stayed there as assistant and docent until Boveri's death in 1915. The personal relations of those years have remained an indelible memory. In addition, there were letters. Boveri was a spontaneous, highly personal correspondent, fond of humor and blunt sayings. Unfortunately a great part of his correspondence, carefully collected after his death by Frau Marcella Boveri, was lost in the bombardment of Würzburg in the Second World War. This material included almost all the replies to Boveri's own letters. By unusual luck, however, a number of letters written by Boveri to his brother and sister-in-law in Baden, Switzerland, became available. There were also letters to August Pauly, with whom Boveri had formed a close friendship in Munich; to Hans Spemann, one of his first doctoral students, who remained in touch with him; and to W. C. Röntgen, his colleague in physics at Würzburg. I express heartfelt thanks to Dr. Margret Boveri, the daughter of Theodor and Marcella Boveri, and to Kurt Iseman, M.D., the son-in-law of August Pauly, for giving all this private and precious material into my hand. 